\title{
Ante la reforma del Régimen local
}

\author{
José Ignacio Morillo-Velarde Pérez \\ Catedrático de Derecho Administrativo \\ Universidad Pablo de Olavide
}

SUMARIO: I. INTRODUCCIÓN. ALGUNAS CONSIDERACIONES SOBRE LA SITUACIÓN ACTUAL DE LA AUTONOMÍA LOCAL. 1. Competencias municipales y autonomía local. 2. Autonomía local y uniformismo municipal. II. LA ORIENTACIÓN DE PROYECTO DE LEY DE MEDIDAS PARA LA MODERNIZACIÓN DEL GOBIERNO LOCAL. 1. La organización de los municipios de gran población. 2. De nuevo las competencias municipales y una propuesta para concluir.

\section{INTRODUCCIÓN. ALGUNAS CONSIDERACIONES SOBRE LA SITUACIÓN DE LA AUTONOMÍA LOCAL}

\section{Competencias municipales ${ }^{1} \mathrm{y}$ autonomía local}

Aún no apagado el eco de las últimas elecciones locales, a punto de constituirse las nuevas corporaciones, en medio del rumor de los consabidos pactos postelectorales, el Gobierno presenta a las Cortes Generales el Proyecto de Ley de Medidas para la Modernización del Gobierno Local (Boletín Oficial del Congreso de los Diputados de 13 de junio de 2003), un texto esperado, aunque quizá con otra orientación. Basta con una ligera ojeada para advertir su importancia. Pero si el proyecto en sí es importante, más importancia tiene su significado de cara al conjunto de nuestro régimen local. En efecto, en la exposición de motivos se anuncia como horizonte de un futuro, que esperemos no sea lejano, la elaboración de una nueva Ley de Bases de Administración Local que constituya un instrumento adecuado para que nuestros gobiernos locales afronten los complejos retos que les presentan los albores del siglo XXI, que necesitará un tiempo razonable pero no dilatado de reflexión y discusión. A colaborar a dicha reflexión se destina este trabajo con el que quiero unirme al homenaje al profesor Sebastián MartínRetortillo, para concluir con la propuesta de una fórmula para el despliegue de la autonomía municipal mediante la determinación de sus competencias propias y la formulación de un nuevo concepto de éstas.

A nadie se oculta que no preocupó demasiado el gobierno local cuando se debatió la Constitución. Ni entonces ni en los primeros momentos de su

\footnotetext{
${ }^{1}$ Se alude a las competencias propias.
} 
desarrollo, los problemas locales lograron una respuesta acorde con lo que después se ha revelado como una de las nuevas claves constitucionales, a pesar de la propia jurisprudencia del Tribunal Constitucional y la consiguiente adaptación de la legislación tradicional, o quizá por ellas mismas, pues generaron la falsa convicción de que todo estaba resuelto o en vías de resolución. Pesaba mucho más la necesidad de asegurar la andadura de las recién creadas Comunidades Autónomas que reformar con la necesaria profundidad la legislación sobre régimen local.

En 1978 se reformó el régimen electoral de las Entidades locales para ajustarlas a las exigencias de representatividad que exigía el nuevo contexto, requisito mínimo imprescindible después de la larga etapa franquista. En 1981 se suprimieron las ataduras y las tutelas, pero en 1985, cuando correspondía una reforma profunda y ajustada a la Constitución, no se hizo en realidad otra cosa que un acicalamiento de las fórmulas tradicionales, amparándose en la técnica de la garantía institucional ${ }^{2}$ que, al decir de la mayoría de la doctrina seguida por el Tribunal Constitucional, constituía la garantía que dispensaban los artículos 137 y 140 a 142 CE a la autonomía local. Es verdad que este instrumento se consideró entonces doctrinalmente satisfactorio y políticamente útil. No se reparaba demasiado en que si con ello justificaba la actitud de los constituyentes de resolver la regulación local con unos genéricos preceptos que a bastante poco comprometían, difícilmente podía aplicarse entre nosotros una garantía que remitía el contenido de la autonomía local a la recognoscibilidad social ${ }^{3}$ de algo nunca conocido ni experimentado, pues no puede decirse que en España haya existido en algún momento verdadera autonomía local ${ }^{4}$. Se era muy consciente, sin embargo, de que con ello nada se podía empeorar dada la situación de partida en el régimen político anterior, al tiempo que se daba un compás de

\footnotetext{
${ }^{2}$ Por todos las referencias contenida en A. EMBID IRUJo, «Ordenanzas y reglamentos municipales» Tratado de Derecho Municipal, segunda edición, dirigido por S. MuÑoz Machado, Civitas, 2003, tomo I, p. 509.

${ }^{3}$ L. ORTEGA, «Las competencias como paradigma de la autonomía local». Justicia Administrativa Extra 2000.

${ }^{4}$ Esto no significa que en España se haya desconocido la existencia de ámbitos de interés de los municipios. Conceptos como el de gobierno interior de los pueblos frente a su gobierno político, administración separada, etc., lucen desde las primeras normas reguladoras de las estructuras municipales en los albores del constitucionalismo. No existía, sin embargo, la conciencia de que tales intereses tuvieran la consideración de intereses públicos ni que fuesen oponibles frente al Estado, única otra fuente de poder completamente centralizado. Lo que realmente faltaba era la conciencia de la respetabilidad de tales intereses desde ámbitos superiores y obviamente los mecanismos para ello. Pero es evidente que casi desde el comienzo se era consciente de la diferenciación de estas entidades - los pueblos — sobre los que andando el tiempo se habría de verter no poca retórica encubridora del más crudo centralismo.
} 
espera hasta que llegara el momento oportuno para ocuparse de estos asuntos. Se soslayaba así que la Constitución no contuviera atribución directa de contenidos funcionales concretos ${ }^{5}$ a los municipios y que la Ley $7 / 1985$, de 2 de abril, Reguladora de las Bases del Régimen Local (LRBRL) ${ }^{6}$, siguiera en la misma tónica dejando en manos de las Comunidades Autónomas y, en menor medida, del Estado la concreción en competencias de los ámbitos de intereses de los entes locales. Realmente ocurría que no se tenía una conciencia cabal de cuales eran las auténticas exigencias de la autonomía local y de la naturaleza de unos entes a los que se seguía incardinando en el ámbito del poder ejecutivo.

Consolidadas la Comunidades Autónomas ${ }^{7}$ que, además, en muchos casos han ejercitado plenamente sus competencias de desarrollo de régimen local, desde hace años — casi tras las elecciones locales de 1979- se hace notar el clamor de unas corporaciones locales, representativas, democráticas y responsables ante sus ciudadanos, que ven como ni sus competencias ni sus medios están a la altura de lo que éstos les exigen. La insuficiencia del marco funcional ${ }^{8} \mathrm{y}$ organizativo que regulan las actuales bases y su desarrollo autonómico cada vez se hace más patente. Durante estos años se ha creado una conciencia social de autogobierno que empieza a servir de contraste con la realidad normativa ${ }^{9}$, por más que todavía

\footnotetext{
${ }^{5}$ Nuestra propia experiencia había demostrado que las largas enumeraciones de competencias locales no siempre eran satisfactorias y, con independencia del talante centralista y autoritario del régimen anterior, el vaciamiento de las competencias contenidas en el art. 101 de la Ley de Régimen local de 1955 era un hecho todavía reciente que se había impuesto también por la necesidad.

${ }^{6}$ Me parecen excesivamente optimistas las valoraciones que acerca de esta Ley hace L. PAREJO ALFONso, «La autonomía local en la Constitución» Tratado de Derecho Municipal, segunda edición, dirigido por S. MuÑoz MACHADO, Civitas, 2003, tomo I, p. 29. Una cosa es que en ese momento difícilmente se pudiera hacer una Ley muy diferente y otra otorgarle una virtualidad ordenadora que ha resistido casi veinte años de historia. Sus insuficiencias se vienen haciendo sentir hace mucho tiempo, lo que ocurre es que ni hay claridad de ideas ni una voluntad política suficiente para plantear una alternativa, pues las reformas de 1999 fueron de entidad mínima y el proyecto de ley que se comenta en estas páginas abre una tímida ventana a un panorama nuevo que no se acaba de concretar.

${ }^{7}$ El patrón alemán de la garantía institucional que la doctrina y la jurisprudencia constitucional aplicaron a la interpretación de la Constitución de 1978, aparte de las dificultades derivadas de la propia construcción doctrinal, chocó con el momento histórico de la necesidad de afirmación de las Comunidades Autónomas, que no podían sino ver en las Entidades Locales y sobre todo en las más robustas, si es que puede hablarse así, rivales a los que no se podía potenciar. A ello habría que añadir problemáticas más concretas de carácter local o territorial.
}

${ }^{8}$ Una cumplida explicación del sistema, por todos y muy actual J.M. BAÑo LEóN, «La ordenación de las normas reguladoras del régimen local» Tratado de Derecho Municipal, segunda edición, dirigido por S. MuÑoz Machado, Civitas, 2003, tomo I, p. 458.

${ }^{9}$ Una sucinta síntesis de la historia postconstitucional en L. PAREJo Alfonso, «La autonomía local en la Constitución» Tratado de Derecho Municipal, segunda edición, dirigido por S. MuÑoz MACHADO, Civitas, 2003, tomo I, p. 26. 
queden vigentes numerosos prejuicios arrastrados por dos siglos de efectivo centralismo exacerbado en el régimen precedente. El referente que no puede encontrarse en la historia ha nacido en el momento presente y se expresa a través del descontento de las propias corporaciones representativas que trasladan una clara conciencia social de reproche, acusadora de insuficiencia y se plasma, en muchas ocasiones, en conductas que, en puridad, no pueden sino calificarse de ilegales, por más que benignas —no digo que no sean razonables- interpretaciones jurisprudenciales o doctrinales puedan justificarlas.

Las cosas no podían suceder de otra manera: instauradas unas entidades locales democráticas y proclamada su autonomía, aunque ésta careciera de concreción constitucional e incluso legal, deferida a los vagos parámetros que comporta la teoría de la garantía institucional, la tensión estaba servida. Era cuestión de tiempo que se echasen en falta contenidos tangibles, susceptibles de producir logros efectivos mensurables por los ciudadanos que se dirigen con sus demandas a estas entidades, pues no en vano constituyen el escalón del poder público más próximo a ellos. Hace ya años la doctrina se viene haciendo eco de esta realidad ${ }^{10}$. Es conocido también cómo esta tensión ha desembocado en el proceso en el que hoy nos hallamos inmersos bajo denominaciones diversas: Pacto local, segunda descentralización, etc. La realidad es que son ya varios los años transcurridos desde que el 24 de septiembre de $1996^{11}$ la Comisión Ejecutiva de la Federación Española de Municipios y Provincias aprobase un importante documento denominado Bases para el Pacto Local, en el que puede encontrarse el punto de partida de la reacción frente a una situación que parece no gustar a nadie pero de la que tampoco parece fácil salir ${ }^{12}$. Creo que existe bastante acuerdo en que las medidas legislativas en que se concretó del modo más visible el pacto local, las leyes de abril y de mayo de 1999, fueron insuficientes. Se desprende con claridad de las sugerencias doctrinales, sobre todo de aquellas que intentan superponer a nuestro Derecho vigente, de modo singular al artículo 25 LRBRL, los logros y avances de la doctrina y jurisprudencia alemanas y las exigencias de la Carta Europea de la Autonomía Local que han tenido también algún reflejo en nuestra juris-

\footnotetext{
${ }^{10}$ T. FonT I Llovet, «La autonomía local en España a los veinte años de la Constitución: perspectiva de cambio», Anuario de Gobierno Local. 1998, M. Pons, 1999, p. 16.

${ }^{11}$ Obviamente muchos más si nos remontamos al Congreso de La Coruña de la FEMP de 1993.

${ }^{12}$ Un diagnóstico de la situación entre otros que se viene haciendo en estos últimos años en L. ORTEGA, «Reformas en el sistema de gobierno municipal», Anuario de Gobierno Local 1998, M. Pons, 1999, p. 59.
} 
prudencia ${ }^{13}$. Particular interés reviste, a mi juicio, el intento de revitalizar la cláusula general de competencia municipal ${ }^{14}$ pretendidamente contenida en el párrafo 1 de ese artículo frente a la insatisfactoria situación a que ha dado lugar la cicatería del legislador sectorial estatal y especialmente autonómico a la hora de atribuir competencias a los municipios. Una interpretación del estilo de la que se ha realizado sólo sería posible, a mi juicio, cambiando el texto del artículo 7. 1, párrafo segundo LRBRL, que exige ley para la determinación de las competencias propias.

Estas posiciones, conviene notarlo aquí, están dejando paso a intentos de una comprensión más exacta de la naturaleza de las ordenanzas locales y su posible papel de instrumentos de autoatribución de potestades para superar las insuficiencias de la legislación sectorial ${ }^{15}$, pieza clave para el correcto funcionamiento del sistema.

Todos estos esfuerzos doctrinales no hacen sino poner de manifiesto lo obsoleto de una legislación promulgada cuando aún no se tenía una idea cabal de cuál era el auténtico sentido de la autonomía local, a la que se relegaba a la condición de simple autonomía administrativa - hoy sabemos que siendo diferente de la autonomía que la Constitución reconoce a las Comunidades Autónomas es, sin embargo, autonomía política- y, en consecuencia, se propiciaba un concepto meramente corporativo de las Entidades locales.

Si las cosas fueran simplemente así, quizá los aludidos esfuerzos doctrinales serían suficientes; pues bastarían para la comprensión y superación de

\footnotetext{
${ }^{13}$ T. Font I Llovet, «La autonomía local en España a los veinte años de la Constitución: perspectiva de cambio», Anuario de Gobierno Local. 1998, M. Pons 1999 y «La evolución del régimen local en España», Anuario de Gobierno Local 1999/2000, M. Pons, 2000. J.M. BAÑo LeóN, «La ordenación de las normas reguladoras del régimen local», Tratado de Derecho Municipal, segunda edición, dirigido por S. MuÑoz MACHADO, Civitas, 2003, tomo I, p. 465.

14 J.L. CARRo FernándEZ-VALMAYor, «La cláusula general de competencia municipal», Anuario de Gobierno Local1999/2000, M. Pons, 2000. Excelente trabajo, pero un esfuerzo que, a mi modo de ver, no logra romper con el peso restrictivo que de cara a la atribución de competencias a los municipios se contiene en el concepto que de competencias propias ofrece el art. 7 LRBRL, que exige ley para su atribución. Como digo en el texto, la situación actual no puede superarse por vía de interpretación, se impone la reforma para la que estos trabajos doctrinales constituyen una inestimable ayuda.

15 C. Pareja i Lozano, «Autonomía y potestad normativa de las corporaciones Locales», Revista de Derecho Administrativo, núm. 138, 1995. También sobre la conexión entre competencias locales y potestad reglamentaria local. Por todos las referencias contenida en A. EMBID IRUjo, «Ordenanzas y reglamentos municipales» Tratado de Derecho Municipal, segunda edición, dirigido por S. MuÑoz MaChado, Civitas, 2003, tomo I, p. 516 y especialmente 532 y ss.
} 
una situación insatisfactoria ${ }^{16}$. El problema, en mi opinión, lo ha creado precisamente la concepción tan estrecha de competencias propias que late en el artículo 7. $1 \mathrm{y}$, por lo mismo en el artículo 25. 2 LBRL, al hacer pasar el contenido de la autonomía local por una atribución de competencias que han de efectuar en importante medida las Comunidades Autónomas, hecho que no ocurre con la frecuencia y amplitud deseable ${ }^{17}$. Al mismo tiempo esto ha generado una fuerte conciencia, en la que se escuda el Estado, de falta de competencia para atribuir cometidos a los entes locales, pues ello supondría, se dice, invadir las competencias autonómicas. Así como las conductas obstaculizadoras de la autonomía local se concretan en omisiones, raras veces en actuaciones positivas que entonces han controlado y, en ocasiones corregido, el Tribunal Constitucional e incluso el Tribunal Supremo, nos debatimos en la actual situación en que el Estado se considera satisfecho por su actuación con las reformas de 1999 y echa la pelota al tejado de las Comunidades Autónomas para que continúen con la segunda descentralización a través de pactos locales en su respectivo ámbito ${ }^{18}$. Para complicar más las cosas y obstaculizar aún más una solución que pudiera considerarse satisfactoria desde la perspectiva de la autonomía local no faltan quienes atribuyen a los tímidos esfuerzos estatales una intención política encaminada a debilitar a las Comunidades Autónomas.

De todo lo dicho se concluye que no puede salirse del atolladero sin una reforma de la Ley Reguladora de las Bases del Régimen local, en especial la referencia a la ley para determinar las competencias propias de los municipios por lo que aquí interesa, que es lo que limita el alcance del artículo

\footnotetext{
${ }^{16}$ Reconociendo el valor de estos esfuerzos y la formulación de principios a través de los que se pone de manifiesto aún más la insuficiencia de la legislación actual (subsidiariedad, presunción de competencias locales, prevalencia de la voluntad local), creo conveniente llamar la atención sobre el alcance de los mismos, pues a veces se puede resolver un problema creando otro mayor. Sin ánimo de realizar una crítica completa que nos alejaría del propósito de estas páginas, entiendo que conviene refrenar el entusiasmo por los principios, en especial cuando se trata de principios noveles, por muy atractivos que pudieran parecernos. Así ocurre, a mi modo de ver y lo digo simplemente a título de ejemplo, con el que se ha calificado principio de prevalencia de la voluntad local, ideal en el marco en que nos estamos moviendo, como fácilmente se comprende, pero, tal como se ha planteado, conduce a una elección que hace un órgano judicial — aunque sea el Tribunal Supremo - rectificando la realizada por el legislador. T. FONT I LlovET, «La autonomía local en España a los veinte años de la Constitución: perspectiva de cambio», Anuario de Gobierno Local. 1998, M. Pons, 1999, p. 26.

${ }^{17}$ Excelente síntesis del problema en T. FonT I LLOVET, «La autonomía local en España a los veinte años de la Constitución: perspectiva de cambio», Anuario de Gobierno Local. 1998, M. Pons, 1999, p. 25. También es muy interesante J. GARCía RoCA, «El concepto de autonomía local según el bloque de la constitucionalidad», REALA, núm. 282, 2000.

${ }^{18}$ Sobre el pacto local y las medidas adoptadas por algunas Comunidades Autónomas para su desarrollo vid. M. Arenilla Sáez y J.M. Canales Aliende, Gobierno y Pacto Local, Colección Estudios BOE, Madrid, 1999.
} 
25 LRBRL. Ha llegado el momento de prescindir de la legislación sectorial como instrumento principal de atribución de competencias y de dar su verdadero valor a la cláusula del artículo $25 \mathrm{LRBRL}^{19}$, aunque también sea preciso salvaguardar las competencias de las Comunidades Autónomas. La gran cuestión es: ¿es, acaso, esto posible? ¿Cómo? Y, en tal caso, ¿quién puede hacerlo? Volveré más adelante sobre estas cuestiones.

\section{Autonomía local y uniformismo municipal}

El principio de uniformidad ha sido uno de los que tradicionalmente han configurado las estructuras organizativas locales en nuestro Derecho. Con ligeras quiebras - de sobra conocidas - se mantiene una estructura uniforme con independencia de la envergadura real de las concretas organizaciones municipales y de la complejidad de las competencias que gestionan y de los servicios que prestan. Esta situación legal no impide que los municipios, haciendo uso de su potestad de autoorganización, incorporen fórmulas de gestión que introducen una cierta matización de variedad sobre unos esquemas fundamentalmente idénticos. Ni que decir tiene que, al par que los municipios se han dotado, por mandato de la CE, de órganos de gobierno representativos y democráticos y se enfrentan a cometidos que exceden las entecas competencias que derivan de la LRBRL y normas de desarrollo, para cumplir con papeles de liderazgo social y de dinamización e impulso de las sociedades en que se insertan, reclaman con fuerzas estructuras adecuadas con las que hacer frente a nuevas misiones que, quizá, nunca hasta el momento se ha pensado que podrían ser de su incumbencia. No sorprende, por tanto, que desde la doctrina empiece a reclamarse el carácter básico de la diversidad. Y, aunque a primera vista pudiera parecer de otra manera, no estamos ante una paradoja, sino ante exigencias que derivan de la diferente situación funcional que expresa la autonomía municipal, que pueden ser reconocidas en el nivel básico de la legislación estatal ${ }^{20}$.

\footnotetext{
${ }^{19}$ Mientras no se haga así las referencias doctrinales que he señalado en notas anteriores y otras, que seguramente se me habrán pasado, serán dignas de todo aplauso, demuestran un altísimo nivel en la capacidad de construcción jurídica de sus autores y en su sensibilidad democrática, pero chocan contra la Ley, nos guste o no. La siguiente consecuencia es obvia: no parece que se encuentren en muy buena posición los municipios para plantear necesidades de financiación del ejercicio de unas competencias cuya legalidad pueda ser discutida. En relación con las competencias propias también puede consultarse L. ORTEGA ÁlvareZ, «Las competencias propias de las Corporaciones Locales» en Tratado de Derecho Municipal, segunda edición, dirigido por S. MuÑOZ Machado, Civitas, 2003, tomo I.

${ }^{20}$ T. FonT I LLOVET, «La evolución del gobierno local en España: de los nuevos principios a la geometría variable», Anuario de Gobierno Local 1999/2000, Marcial Pons, 2000, p. 33.
} 


\section{LA ORIENTACIÓN DE PROYECTO DE LEY DE MEDIDAS PARA LA MODERNIZACIÓN DEL GOBIERNO LOCAL}

Situados aquí resulta esperanzador, al tiempo que preocupante, el texto del Proyecto de Ley de Medidas para la Modernización del Gobierno Local. Es esperanzador en lo que contiene y preocupante por lo que omite, aunque con optimismo quiero pensar que las omisiones no tienen especial significación ateniéndonos a su carácter de texto experimental que avizora una reforma profunda del régimen local español, de la que no constituye sino un avance que no cierra ninguna posibilidad.

El Proyecto de Ley a que se refieren estas páginas versa sobre aspectos muy diversos, aunque sólo he querido referirme a dos: uno de ellos porque es el que más extensión ocupa y se presenta como más novedoso, que entronca con los que, al parecer, fueron los orígenes de esta reforma: el régimen de las Grandes Ciudades, que ahora ha quedado concretado en el régimen de los municipios de más de 250.000 habitantes. Indudablemente es una temática en sí misma completa, suficiente para caracterizar una norma y justificar una reforma, incluso si se me apura, suficiente para acaparar el protagonismo de una reforma como ésta, eclipsando otros contenidos menos aparatosos. Suficiente también para justificar un trabajo de más envergadura que éste. El otro aspecto -fácil es observarlo- se encuentra por completo ausente del texto legislativo proyectado. Me refiero a las competencias municipales. En efecto, no hay ninguna alusión al respecto en el Proyecto. Es esta omisión conectada con la referencia a los aspectos organizativos lo que cierra el perfil de esta reflexión.

Aunque la aludida omisión tiene, sin duda, una clara explicación, creo que estamos ante una incoherencia. ¿Para qué articular una organización que empieza a romper los moldes tradicionales de la Administración local si se sigue asignando a estas entidades los mismos cometidos? La incoherencia señalada parece salvarse porque en el fondo lo que ocurre es que se sabe muy bien que las competencias de los municipios no son las que se desprenden de la lógica del artículo 25. 2 LRBRL sino que éstos, desbordando esa estrecha franja, insatisfactoria para los vecinos, en definitiva los electores, se han deslizado hacia la realización de cometidos necesarios para la satisfacción de las necesidades y aspiraciones de su comunidad, al margen de toda atribución legal. De ello es prueba esa benévola jurisprudencia de que hablaba más atrás y las justificaciones doctrinales de que he tratado al comienzo.

En el marco de la gestión de los servicios públicos que las leyes les asignan, los municipios se sienten responsables en términos socioeconómicos 
del desarrollo y bienestar de la colectividad a la que institucionalizan y no reparan en medios para implicarse en su consecución con los consiguientes problemas de legalidad en muchas ocasiones y financieros en casi todas, por no decir que siempre. Esta suerte de implicaciones necesariamente aboca a una organización capaz de acoger en su seno la especialización funcional, que no otra cosa representa el modelo organizativo de las llamadas Administraciones superiores apoyado en el patrón departamental. El tradicional prejuicio que ha visto en las Administraciones locales organizaciones representativas es lo que ha determinado su corporativismo, que ahora parece repudiar la exposición de motivos del texto que comento, justificado en la sencillez cuando no en la simplicidad de unos cometidos que podían ser abarcados por vecinos con sentido común y una formación media. Esta situación desde tiempo atrás hace aguas en muchos municipios. Se vive mal que bien en unos moldes que no son los adecuados y que ahora, al menos para algunos municipios, se desea superar. El problema es que el prejuicio tradicional parece haber plasmado incluso en el propio texto constitucional, en las breves pero claras líneas organizativas que traza para los municipios en el artículo 140. Queriendo reforzar su carácter representativo y democrático, objetivo que debe valorarse del modo más positivo, se está acogiendo al mismo tiempo una estructura inadecuada para muchos supuestos. De esta manera, se constata un importante obstáculo a las posibilidades innovativas del porte de la que ahora se pretende. Este tributo al pasado muestra cómo el aparcamiento de los temas locales cuando se elaboró la Constitución no respondía a una concepción de esas realidades acordes con los nuevos principios, sino únicamente a una táctica derivada de la prioridad de resolver cuestiones más perentorias en relación con la organización territorial del Estado, como es el resto de la materia del Título VIII. La invocación de la técnica de la garantía institucional que, como hemos visto, salvó la ausencia de toda mención al contenido de la autonomía que se garantiza (arts. 137, 140, etc.) no puede venir ahora en nuestro auxilio para allanar el obstáculo que contemplamos hacia fórmulas organizativas más satisfactorias. Así parecen haberlo entendido los redactores del Proyecto de Ley evitando llevar hasta sus últimas consecuencias el desarrollo de la estructura a la que apuntan.

Desde el punto de vista de la organización municipal, el Proyecto de Ley contiene dos tipos de medidas que configuran el alcance de la reforma. Unas - reforma de los artículos 20, 21, 22 y 23 LBRL- suponen un nuevo retoque de la organización de los municipios sobre el esquema de la Ley de 1985, en el mismo sentido que se hiciera en 1999. No me voy a ocupar aquí de estas medidas, pues si bien son importantes, no tienen la significación que deseo destacar en estas reflexiones. Las otras, las más 
originales, integran el nuevo Título $\mathrm{X}$, bajo la rúbrica Régimen de los municipios de gran población; en ellas quiero centrar estas reflexiones para salir al paso de algunas posibles reservas sobre su constitucionalidad $\mathrm{y}$, sobre todo, intentar abrir horizontes en este plano.

\section{La organización de los municipios de gran población}

Por tales se entiende en el proyecto a los de más de 250.000 habitantes, capitales de provincia de más de 200.000 habitantes o sede de la capitalidad de Comunidad Autónoma, si así se decide por su Asamblea Legislativa, obviamente en el caso de que no llegasen a esos topes de número de habitantes.

Lo más interesante de la organización que se proyecta es el claro deslinde institucional que ahora se diseña entre - por un lado- las estructuras organizativas ejecutivas y de impulso y dirección política que se atribuyen al Alcalde, asistido por la Junta de Gobierno Local que colabora con aquel mediante el ejercicio de las funciones ejecutivas y administrativas que la ley le señale y — por otro lado- el Pleno del Ayuntamiento, órgano de la máxima representación política de los ciudadanos en el que residen las competencias normativas, el control y fiscalización de los órganos de gobierno y la adopción de los acuerdos más relevantes para el desarrollo de la vida del municipio.

El Pleno, cuya presidencia el Alcalde puede delegar en un Concejal, tiene su propia organización cifrada en las Comisiones y el Secretario del Pleno frente a la que se alza como novedad el conjunto constituido por el Alcalde y la Junta de Gobierno Local que, deseo subrayar, tiene sus competencias propias, muchas de ellas no delegables y otras, las que podríamos calificar de más estrictamente ejecutivas, delegables en los miembros de la propia Junta o en los Secretarios Generales, Directores Generales u órganos similares que el proyecto prevé —artículo 127-. La Junta de Gobierno Local cuenta con su Secretaría desempeñada por un Concejal miembro de dicha Junta, designado por el Alcalde. La Junta de Gobierno y el Concejal-Secretario estarán dotados de un órgano de apoyo nombrado por la propia Junta entre funcionarios de Administración local con habilitación de carácter nacional. Esta incipiente organización ejecutiva se completa con la asesoría jurídica, con independencia de las funciones del Secretario del Pleno, con el objeto de asesorar al Alcalde, a la Junta de Gobierno Local y a los órganos directivos, además de la defensa en juicio del Ayuntamiento, sin perjuicio de lo dispuesto en el artículo 447 de la Ley 
Orgánica 6/1985, de 1 de julio, del Poder Judicial. Se cierran los elementos organizativos con la clasificación de los órganos en superiores (Alcalde y miembros de la Junta de Gobierno local) y directivos (Secretarios Generales de cada Área o Concejalía, Directores Generales, titular del órgano de apoyo a la Junta de Gobierno Local y al Concejal-Secretario de la misma, titular de la asesoría jurídica, titular del órgano de gestión económica-financiera y presupuestaria e interventor general municipal), etc.

El Proyecto de Ley no completa el diseño de una organización municipal concreta que queda en manos del desarrollo que de estas bases puedan hacer las Comunidades Autónomas y la propia potestad de autoorganización de los municipios, pero ofrece las piezas para un profundo cambio, sin merma naturalmente de la pervivencia de rasgos tradicionales que, por otro lado, constituyen un límite consagrado en la Constitución. Efectivamente, no podemos olvidar que el artículo 140 atribuye el gobierno y la administración de los municipios a los Ayuntamientos compuestos de Alcalde y Concejales. Se establece así un pie forzado de necesaria observancia que conecta con elementos tradicionales de nuestro régimen local. Dentro de ese marco la organización, cuya regulación se prevé en los artículos 126, 127, 129130 y concordantes del Proyecto, evidencia un claro acercamiento de la estructura organizativa municipal tradicional a la propia de una Administración departamental.

Se aboca así a una situación que aparentemente, al menos, se presenta paradójica y poco comprensible. Las Ciudades Autónomas de Ceuta y de Melilla $^{21}$ tienen una organización administrativa basada plenamente en el modelo departamental, como se desprende con claridad de sus Estatutos, mientras que otras ciudades, quizá con problemáticas más complejas, sólo con dificultad y en medio de matizaciones podrán aproximarse a ella. La situación reviste pues algo de paradoja, por más que las citadas ciudades tengan obvias peculiaridades. La justificación de la diferencia radica en la habilitación que proporciona la disposición transitoria cuarta de la Constitución que permitió constituirlas en Comunidades Autónomas. Se trata, pues, de una justificación formal, por más que no pueda considerarse arbitraria, dada la peculiar situación de dichas ciudades. Pero si esto es ciertamente así y no se cuestiona aquí, también pueden aducirse razones de mucho peso que justifican una organización análoga para otras ciudades y pueblos. Ello será posible sólo con matizaciones y salvedades, como hemos de ver.

${ }^{21}$ Ley Orgánica 1/1995, de 13 de marzo, Estatuto de Autonomía de Ceuta y Ley Orgánica 2/1995, de 13 de marzo, Estatuto de Autonomía de Melilla. 
En cualquier caso y al margen de prejuicios, en este caso constitucionalizados, la lección es que la historia parece discurrir en el sentido de que las diversas Administraciones públicas de carácter territorial convergen hacia un modelo unitario, por encima de diversificaciones más o menos ocasionales. Es éste un fenómeno que ahora suscita algunas reflexiones.

Cuando la autonomía de los entes territoriales -léase municipios en este caso- se toma en serio, como autonomía política —atrás quedó el subterfugio de la denominada autonomía administrativa ininteligible y contradictorio - y, por tanto, como verdadera capacidad de autogobierno para solventar sus propios intereses — sean exclusivos o compartidos con otras entidades de ámbito superior, que ahora tanto da- a través de organizaciones de carácter representativo, no hay más remedio que admitir la sustancial identidad entre todos ellos y aceptar la convergencia de sus estructuras organizativas, pues con independencia de la formalidad que diferencia a algunas de sus potestades —en especial la legislativa frente a la normativa de dictar reglamentos u ordenanzas ${ }^{22}$ - debe prevalecer la idea de Administración territorial sobre otras caracterizaciones doctrinales de gran predicamento tradicional. Ha quedado superado el viejo esquema organizativo de los municipios como corporaciones, universitas personarum, titulares de intereses que, al decir de uno de nuestros clásicos, ni son de familia ni son de sociedad, o sea, que no son intereses públicos propiamente, en las que el órgano de representación vecinal constituye la única parte realmente sustancial de la organización, a diferencia de lo que ocurre con las Administraciones estatal y autonómicas — las llamadas Administraciones superiores, que, como tales organizaciones no son representativas, pero no por ello, menos democráticas- en que por aplicación del principio de separación de poderes el órgano de representación y control con poderes legislativos quedaba fuera de la Administración, al par que la Administración, dotada incluso de personalidad jurídica era ese complejo burocrático - calificado como persona jurídica de naturaleza fundacional, universitas rerum - de carácter instrumental al servicio de los fines fijados por el legislador.

Era el esquema organizativo correspondiente a la concepción de la Administración local como Administración indirecta, apéndice del poder ejecutivo en el que se incardinaba. Era la idea de los Ayuntamientos como agentes subordinados del poder ejecutivo como los calificara el conde de

\footnotetext{
${ }^{22}$ No se trata de identificar ambas potestades ni de propugnar la potestad legislativa para las Administraciones municipales, aunque no creo que fuese ningún disparate, bien matizadas y organizadas las cosas. Es evidente que no es éste el modelo que ha establecido la Constitución Española de 1978.
} 
Toreno ${ }^{23}$, que no puede sostenerse una vez proclamada y garantizada la autonomía local. La superación de aquella estructura tradicional se ha producido - conviene destacarlo- precisamente por el impulso democrático procedente de los Ayuntamientos que establecen unas exigencias difíciles, si no imposibles de satisfacer con las estructuras tradicionales. Se tiende, pues, a un acercamiento de los modelos organizativos de muchas Administraciones públicas territoriales.

El modelo de Administración que sirve para las sociedades modernas y de elevada complejidad es el de las llamadas Administraciones superiores, en el que el órgano de representación democrática se segrega del aparato administrativo burocrático que, a su vez, se diversifica en organizaciones especializadas en las materias que gestionen, sin perjuicio por supuesto, de que en último término todo esté integrado en complejos institucionales superiores y se entablen relaciones entre ellos a través de los más variados mecanismos. Este distanciamiento entre las dos partes de la organización permite una gestión y un gobierno más eficaces, compatibles con la supremacía y el control democráticos que siempre habrá de radicarse en el órgano directamente representativo.

El texto que se proyecta para los grandes municipios pretende incorporar una forma de gobierno y administración basada en la dualidad organizativa enfrentando el Pleno del Ayuntamiento al Alcalde y a la Junta de Gobierno Local como órganos de dirección política y de gestión ${ }^{24}$, aunque bajo el amplio paraguas del Ayuntamiento, pues de otro modo chocaría con el artículo 140 de la Constitución. Este dato obliga, a mi juicio, a una reelaboración de las fórmulas teóricas comprensivas de la Administración local, de la misma forma que se impone la necesidad de precisar la comprensión de la potestad normativa local en el marco de la dogmática de la potestad reglamentaria, incluso más allá de sus posibilidades respecto del cumplimiento del principio de legalidad, pero este tema desborda el objeto de este trabajo.

\footnotetext{
${ }^{23}$ A. Posada, La evolución legislativa del Régimen Local en España 1812-1929. Instituto de Estudios de Administración Local, 1982, p. 78.

${ }^{24}$ Me parece significativo a este respecto el siguiente precepto, de acuerdo con la redacción proyectada: art. 70 bis. 3 (la iniciativa) En los municipios a que se refiere el art. 121 de esta Ley, deberá ser informada previamente por la asesoría jurídica regulada en el art. 129, o bien por el Secretario del Pleno previsto en el art. 122. 5, dependiendo del órgano que resulte competente para conocer del mismo (el Alcalde, la Junta de Gobierno Local o el Pleno). Sin embargo, me parece excesiva la atomización para el ejercicio de acciones que deriva de la atribución de esta competencia al Alcalde y a la Junta de Gobierno Local en el ejercicio de sus respectivas competencias. Creo que Alcalde y Junta de Gobierno Local constituyen un complejo orgánico integrado, sin perjuicio de la sustantividad de sus competencias.
} 
En lo que ahora nos interesa creo que el nuevo modelo nos conduce a dos posibles afirmaciones de interés por lo que respecta a la caracterización de estas entidades locales. La primera supone una afirmación de estos municipios como Administraciones territoriales y, en consecuencia, ha de afirmarse respecto de ellos la nota caracterizadora de las Administraciones territoriales, esto es, la de la generalidad de sus fines que justifica una organización del porte de la que se diseña en el proyecto. Esta nota se traduce, a mi juicio, en que la cláusula contenida en el artículo 251 LBRL ha de configurarse verdaderamente como una cláusula general de competencias municipales por ser una exigencia de carácter esencial de los municipios, conectada con lo más íntimo de la autonomía local. En consecuencia, no puede mantenerse el sistema de atribución de competencias municipales mediante la interposición de leyes estatales o autonómicas. Sobre este aspecto, no obstante, volveré más adelante.

Una segunda afirmación conduce a poner de manifiesto la diferencia de la concepción de la Administración municipal frente a otras Administraciones territoriales o, por mejor decir, su nota característica, que deriva de que no hay poder legislativo en sentido estricto en este ámbito de la organización territorial. Los Ayuntamientos de los municipios, dotados de potestades normativas estructuralmente próximas a las leyes, no están dotados de potestad legislativa — curiosamente se habla de legislaturas para designar los mandatos de los Ayuntamientos y Diputaciones- y no existen en nuestro Derecho cauces mediante los que transferirles esta potestad. Ahí radica, a mi juicio, la gran diferencia entre el régimen de los municipios con gran población y las Ciudades Autónomas de Ceuta y de Melilla. Éstas deben su régimen peculiar a una concreta y específica mención constitucional - la disposición transitoria cuarta - que abre un régimen especial al margen del general de los municipios y derivado de ahí a un Estatuto de Autonomía, norma institucional básica de la Comunidad Autónoma (art. 147. 1 CE) que, si bien tampoco les otorga potestad legislativa en la actualidad, nada impide que mediante una reforma se la llegara a otorgar, si las Cortes Generales lo estiman oportuno, pues es un cauce idóneo para ello. No puede hacerse lo mismo por ninguna otra ley —de bases sería en el caso que se analiza- Ni creo que sea pensable un Estatuto que de manera genérica contemplara la posibilidad de atribuir potestad legislativa a un tipo de entes públicos —algunos o todos los municipios- pues estos supuestos no pueden subsumirse dentro de las previsiones constitucionales (art. 144, a). Todo ello desbordaría el planteamiento constitucional del Título VIII, a pesar de su flexibilidad y apertura. Nada de esto es, pues, posible en relación con ninguna de las organizaciones que integran la Administración local. Para acceder a la titularidad 
de la potestad legislativa hace falta su transformación en Comunidad Autónoma como de hecho ha ocurrido en el caso de las Comunidades Autónomas uniprovinciales, pero estas responden a otro fenómeno.

Es la relación con el régimen vigente de las Ciudades Autónomas de Ceuta y de Melilla, como es posible configurar los nuevos municipios - los de gran población- como auténticas Administraciones departamentales en la que se produce plena separación entre la organización ejecutiva y la representativa. En el caso de las Ciudades Autónomas cuyas Asambleas no gozan de potestad legislativa, se encuentra dicha separación con entera naturalidad. Con matizaciones y rebajas éste es, sin embargo, el modelo que se pretende introducir en la Administración local.

En este esquema el grueso de la actividad relacional ha de recaer sobre la organización que encabeza el Alcalde, así se desprende de la lectura de las competencias que se recogen en los artículos 124 y 127 del texto proyectado, mientras éste será un aspecto menos relevante de la actividad del Pleno del Ayuntamiento. No obstante, los actos que éste dicte y las disposiciones que emane, serán actos administrativos y disposiciones de rango inferior a la ley, justiciables ante los Tribunales contencioso-administrativos por lo que parece claro que la posición de estos órganos no puede ser exactamente la misma que la de los Parlamentos en los contextos estatal y autonómico. Ahora bien, salvada esta situación, nada impide aplicar el mismo tratamiento en el sentido de reducir realmente el ámbito de la Administración municipal a lo que podríamos considerar su aparato ejecutivo, aunque naturalmente el Pleno del Ayuntamiento forma parte del complejo institucional propio del municipio -el Ayuntamiento - a semejanza de lo que ocurre en los otros niveles ${ }^{25}$, sin perjuicio naturalmente en el caso que nos ocupa del reconocimiento de la personalidad jurídica plena de los municipios, cuestión que ha resuelto expresamente la propia Constitución (art. 140)

No cabe duda de que la nueva estructura organizativa de los municipios encaja con dificultad en los parámetros constitucionales, si por tales hemos de tener el texto del artículo 140 referido a los aspectos organizativos. Sin embargo, aceptando como se desprende de dicho texto que el gobierno y la administración de los municipios corresponden a los Ayuntamientos compuestos de Alcalde y Concejales, elegidos de la manera que allí se dice, es posible articular una interpretación que de cabida, además, a otros

\footnotetext{
${ }^{25}$ Hay Comunidades Autónomas como Andalucía cuyo complejo institucional, la Junta de Andalucía está integrado por el Parlamento, el Consejo de Gobierno y el Presidente, engarzando en estos últimos la Administración autonómica (art. 24. 1 LO 6/1981, de 30 de diciembre, de Estatuto de Autonomía para Andalucía).
} 
valores constitucionales a los que se trata de servir con la mencionada organización, entre los que destaca el propio de la autonomía local. Se pretende, en definitiva, evitar que la autonomía municipal sea inviable porque la calidad del gobierno y la administración que podría obtenerse en determinados municipios observando la literalidad del precepto citado sea mínima. Efectivamente, el gobierno de las grandes ciudades - y posiblemente también el de otras no tan grandes - no es posible en términos de eficacia siguiendo las pautas organizativas de hace dos siglos. La realidad demuestra que desde órganos como los Plenos de los Ayuntamientos no pueden resolverse problemas de alta complejidad técnica, económica, etc., y otro tanto puede decirse de las actuales Comisiones de gobierno. Hace falta diversificar las tareas, permitir la resolución por expertos y crear estructuras ágiles próximas a los problemas y adecuadas al ejercicio de las técnicas aplicables, como ya se hace en la práctica en muchos casos aunque sin las estructuras organizativas adecuadas. Esto no significa abdicar de los principios democráticos, por lo que el Pleno sigue teniendo la última palabra a través de las técnicas de control y la potestad normativa y, en cualquier caso, todos los órganos están sujetos al principio de legalidad y en último término al juicio de los Tribunales. No parece que con ello pueda quebrar ningún principio constitucional, incluso si se permitiera el ejercicio de competencias administrativas por órganos cuyos titulares no tuvieran la condición de Alcalde ni Concejal, ya que siempre actuarían bajo el marco de la autoridad y supervisión del Pleno del Ayuntamiento y, por supuesto, sometidos al principio de legalidad, como acabo de afirmar. Esto no significa que el modelo tradicional de gobierno y administración municipal sea absolutamente inservible. Siempre existirán pequeños municipios que no necesitarán otra cosa porque en muchos de ellos muchas de las necesidades que se cubren con el nuevo modelo, se satisfacen mejor a través de fórmulas de gobierno supramunicipales en toda su extensión. En estos casos no hay por qué introducir modificaciones sobre una estructura que, ahí sí, da excelentes resultados. No creo, por tanto, que un planteamiento del tipo del que acaba de exponerse pueda razonablemente ser tildado de que contradice la Constitución, pese a posibles apariencias.

Los redactores del Proyecto de Ley de Medidas para la Modernización del Gobierno Local han sido, además, muy cautos en el aspecto que ahora se trata. En efecto, se han cuidado de que la Junta de Gobierno Local -órgano equiparable a un Consejo de Gobierno- que tiene competencias propias, a diferencia de lo que ocurre en el régimen general — art. 23 del proyecto- esté compuesta mayoritariamente por Concejales (art. 126. 2) y sólo la mitad menos uno serán de nombramiento del Alcalde sin necesidad de que posean esa cualidad; por otro lado, no parece que pueda ejer- 
cer competencias de gobierno ningún órgano que carezca de legitimación democrática directa, con la salvedad de lo dicho acerca de la Junta de Gobierno, salvo por vía de delegación, con lo que ello comporta. En definitiva, entiendo que el texto es sumamente respetuoso con la literalidad de la Constitución y si se atiende más al espíritu que a la letra, nuestra norma suprema ofrece más posibilidades que las que ha apurado el Gobierno al presentar este proyecto. De cara, pues, a la futura reforma de la nueva Ley Reguladora de las Bases de la Administración Local pienso que deben apurarse esas posibilidades sobre todo potenciando la potestad de autoorganización de los municipios en el sentido expuesto.

\section{De nuevo las competencias municipales $y$ una propuesta para concluir}

Creo que en términos generales la reforma que se proyecta, al parecer con gran nivel de consenso de las diferentes fuerzas políticas parlamentarias, no puede sino merecer el aplauso, no obstante dejando constancia de que sólo si efectivamente es el pórtico o antesala de una de más envergadura y calado. Aunque no puedo dejar de recelar frente a este tipo de situaciones que al final se enquistan y terminan por obstruir el objetivo al que en su momento parecían apuntar. Por tanto, si esa especie de constante histórica o maldición no llegara a cumplirse en el caso que se contempla, el juicio sobre la reforma ha de ser positivo, aunque no sin importantes reservas de las que ahora solo me parece de interés destacar lo que sigue, en la línea que he ido apuntando a lo largo de estas páginas.

En efecto, a mí al menos me llama la atención toda ausencia de mención a las competencias municipales. También he expuesto una justificación que salva el texto y lo redime de cualquier acusación de incoherencia. Pero no obstante, el reproche subsiste especialmente si observamos el clamor doctrinal que he aludido al comienzo de estas páginas, haciéndose eco de una situación de insuficiencia que sienten los Ayuntamientos y da lugar a pleitos que los Tribunales tienen que saldar acudiendo a principios que evidencian la inadecuación del Derecho positivo, tal como se contiene en los artículos 7. 1 y 25. 2 LRBRL, por insuficientes. Son estos mismos principios (subsidiariedad, prevalencia de la voluntad local, presunción de competencias locales, etc.) los que pugnan por rechazar esta situación ${ }^{26}$. A la vista de todo ello, me parece que ésta era la ocasión idónea para avanzar, especialmente

\footnotetext{
${ }^{26}$ T. Font I LLOvet, «La evolución del gobierno local en España: de los nuevos principios a la geometría variable», Anuario de Gobierno Local 1999/2000, Marcial Pons, 2000, p, 21.
} 
en relación con los grandes municipios. No sé si la omisión ha sido debida a problemas de consenso con las Comunidades Autónomas. Si es así se puede justificar el que se dilate la reforma a esa futura nueva Ley Reguladora de las Bases de la Administración Local, en que con las máximas audiencias y a ser posible con el consenso de las Comunidades Autónomas, se aborde el problema. No digo consenso ni audiencia de los municipios porque la postura de éstos creo que está muy claramente formulada por la FEMP y porque de la fórmula que se propone, entiendo que sólo pueden salir beneficiados y, en cualquier caso, se deja en su mano determinar el alcance de sus competencias propias, como a continuación expondré.

Parece que existe un claro consenso doctrinal en apoyar la cláusula general de competencias que se desprende del artículo 25. 1 LRBRL. De lege ferenda a dicho planteamiento no se puede objetar nada. Mi opinión, sin embargo, es que en este momento choca con la propia historia, pues es sabido como una cláusula análoga a la contenida en el artículo 25. 1 LRBRL existía en el artículo 101 de la Ley de Régimen Local de 1955 y, sin embargo, ante el avance de la legislación sectorial y la propia incapacidad de los municipios, la jurisprudencia y la doctrina terminaron aceptando lo que se denominó el vaciamiento de las competencias locales entendiéndolas como simples expresiones de capacidad. Es cierto que era un contexto político muy diferente, pero es obvio que cuando se promulgó la Ley 7/1985, Reguladora de las Bases del Régimen Local, ya estaba vigente la Constitución y, precisamente con el apoyo de ésta y la técnica de la garantía institucional, se justificó el sistema actual, que no tiene como centro de gravedad la mencionada cláusula general que hoy se trata de revitalizar. Dar viabilidad a dicha cláusula genérica de atribución de competencias a los municipios es una exigencia derivada directamente de la consagración de la autonomía local y de la naturaleza de Administraciones territoriales que corresponde a los municipios. Por más que se pueda pretextar lo contrario, el Estado puede establecer dicha cláusula como norma básica sin agraviar para nada a las Comunidades Autónomas, derogando el párrafo 2 del mencionado artículo 7. 1 LRBRL. Entiendo que con ello no se vulneran las competencias de las Comunidades Autónomas pues, la autonomía local es un principio que necesariamente ha de tenerse en cuenta a la hora de determinar el diseño completo del sistema de distribución de competencias y como tal vincula tanto al Estado como a las Comunidades Autónomas. No es por tanto razonable que la autonomía local deba estar sometida a un doble filtro a la hora de concretar su contenido, el básico y el de desarrollo autonómico ${ }^{27}$. Esta situación ha desem-

\footnotetext{
${ }^{27}$ Con esta afirmación no cuestiono el carácter bifronte de las entidades locales, como han sido calificadas. Creo que es otro asunto diferente.
} 
bocado en que la autonomía local hasta ahora ha quedado en manos de actuaciones legislativas de carácter positivo cuya omisión o insuficiencia son de difícil control constitucional. De ahí que, de entrada, haya que proclamar la cláusula genérica como contenido de la autonomía local: que los municipios en el ámbito de sus intereses puedan ejercer las competencias - potestades públicas sobre materias concretas- necesarias para satisfacer las necesidades y aspiraciones de la comunidad vecinal. La determinación concreta de estas competencias debe realizarse a través de las ordenanzas municipales, en el marco de las competencias estatales y autonómicas, sin perjuicio, por tanto de las competencias que pudieran corresponder al Estado o a las Comunidades Autónomas.

Creo que el legislador básico no se excede de su papel constitucional si establece una determinación legal análoga a la que acaba de formularse, si es posible con el consenso de las Comunidades Autónomas y, en cualquier caso, habiéndolas oído. No creo que con ello se deje inerme a las Comunidades Autónomas frente a sus propias responsabilidades. Se trata de determinar el ámbito de actuación legítima de éstas y de los municipios tomando como parámetro la Constitución, por lo que a nadie se sustrae nada. Además, las ordenanzas locales que concreten las competencias municipales son susceptibles de los oportunos controles de legalidad que existen en la actualidad. Incluso, cabe la posibilidad de que tales controles, hoy reducidos al ámbito judicial, se incrementen con controles administrativos que aseguren el papel que corresponde a las Comunidades Autónomas y al Estado para defender sus propias competencias frente a posibles extralimitaciones de los municipios. No lesiona lógicamente la autonomía local la posibilidad de que el legislador sectorial, estatal o autonómico, al regular las materias de su competencia, restrinja o amplíe las que se hayan autoatribuido los municipios si tal restricción se encuentra fundamentada en las exigencias de un interés público de carácter superior al municipal que haya de prevalecer. Aquí la última palabra corresponderá al Tribunal Constitucional.

Esta manera de colmar la autonomía municipal a partir de una cláusula general de atribución de competencias que no margina al legislador sectorial, pero tampoco queda a sus expensas, obliga, como se ve, a modificar la concepción de las llamadas competencias propias de los municipios. Pero esto es justamente lo que estamos criticando. Lo característico ya no puede ser, a mi juicio, la atribución por la ley. sino lo que se indica en el número 2 de ese mismo artículo: Las competencias propias se ejercen en régimen de autonomía y bajo la propia responsabilidad atendiendo siempre a la debida coordinación en cuanto a su programación y ejecución con las demás Administraciones públicas. 